\title{
How to Resolve Doxastic Disagreement
}

\author{
Peter Brössel and Anna-Maria A. Eder
}

\section{Contents}

1 Introduction 2

2 The Standard Probabilistic Framework 3

2.1 Modeling Doxastic Disagreement . . . . . . . . . . . . . . 3

2.2 Aggregating Credences Within The Standard Framework . . . . . . . . . . . 3

2.2.1 Normative Requirements . . . . . . . . . . . . . . . . . . 5

2.2 .2 Aggregation Rules . . . . . . . . . . . . . . . . . 8

2.2 .3 Jehle and Fitelson's Approach . . . . . . . . . . . . . . . . . . . . . . . . . . . . . . . . 10

2.3 Further Problems . . . . . . . . . . . . . . . . . . . . . 13

3 An Alternative Probabilistic Framework 14

3.1 Modeling Doxastic Disagreement . . . . . . . . . . . . . . . . . 14

3.2 Splitting the Difference, Revised . . . . . . . . . . . . . . . 15

4 Conclusion $\quad 19$ 


\section{Introduction}

Doxastic disagreement between (epistemic) agents is one of the biggest challenges of social epistemology. Roughly speaking, two agents are in doxastic disagreement with respect to a proposition if and only if (iff) they have different doxastic attitudes towards that proposition. For instance, two agents are in doxastic disagreement when the first agent believes a proposition and the second does not, or when both have different credences (i.e. degrees of belief) in the same proposition. For illustration, let us consider a stock example of a special kind of doxastic disagreement-peer disagreement:

You and your friend have been going out to dinner together regularly for many years. You always tip 20\% and split the check (with each person's share rounded up to the nearest dollar), and you each do the requisite calculation in your head upon receiving the check. Most of the time you have agreed, but in the instances when you have not, you have taken out a calculator to check; over the years, you and your friend have been right in these situations equally often. Tonight, you figure out that your shares are $\$ 43$, and become quite confident of this. But then your friend announces that she is quite confident that your shares are $\$ 45$. Neither of you has had more wine or coffee, and you do not feel (nor does your friend appear) especially tired or especially perky. How confident should you now be that your shares are \$43? (Christensen 2009: 757)

A number of epistemologists agree that there are cases of doxastic disagreement, such as this one, in which one is rational in revising one's epistemic state. However, there is no consensus on how to do that. In this paper, we make considerable progress in answering the question of how to (rationally) revise one's epistemic state in the light of doxastic disagreement, if one is rational in revising one's epistemic state.

Section 2 introduces the standard probabilistic framework for modeling epistemic states. We discuss normative requirements as well as rules, which have been proposed in the literature, for how to (rationally) revise one's epistemic state in the light of doxastic disagreement within this framework. On the one hand we demonstrate that it is not possible to simultaneously satisfy all these normative requirements. On the other hand we argue against the various rules that have been suggested. Furthermore it is shown that the standard framework cannot be used to model other important kinds of epistemic disagreement besides doxastic disagreement. Section 3 argues for a new and purely philosophical solution to the problem of doxastic disagreement. In particular, Section 3 provides a new probabilistic framework for modeling epistemic states, which allows us to model different kinds of epistemic disagreement. Finally, we argue that within this new probabilistic framework it is possible to provide an adequate answer to the question of how to rationally revise one's epistemic state in the light of epistemic disagreement. 


\section{The Standard Probabilistic Framework}

\subsection{Modeling Doxastic Disagreement}

The standard probabilistic framework for modeling epistemic states presupposes the following:

Monistic Bayesianism First, a (rational) agent's epistemic state is best represented by her (rational) credences alone. Second, (rational) credences obey the probability calculus and they are updated by strict conditionalization. ${ }^{1}$

Let us discuss Monistic Bayesianism in more detail: First, it requires that credences obey the probability calculus. Probabilities are defined as follows: Let $\Omega$ be a set of possibilities (e.g., possible worlds, we assume that $\Omega$ is finite) and let $\mathcal{A}$ be an algebra of subsets over $\Omega$. A function $\operatorname{Pr}: \mathcal{A} \rightarrow \mathbb{R}$ is a probability function on $\mathcal{A}$ iff for all propositions $A, B \in \mathcal{A}$ : (i) $\operatorname{Pr}(A) \geq 0$; (ii) if $A=\Omega$, then $\operatorname{Pr}(A)=1$; (iii) if $(A \cap B)=\varnothing$, then $\operatorname{Pr}(A \cup B)=\operatorname{Pr}(A)+\operatorname{Pr}(B)$; and, finally, (iv) if $\operatorname{Pr}(B)>0$, then $\operatorname{Pr}(A \mid B)=\operatorname{Pr}(A \cap B) / \operatorname{Pr}(B)$ [definition of conditional probability]. Second, it requires that credences are updated by strict conditionalization. That is, that if $\operatorname{Pr}_{t_{0}}$ is the agent's credence function at time point $t_{0}, A$ is the logically strongest proposition that the agent became absolutely certain of between time points $t_{0}$ and $t_{1}$, and $\operatorname{Pr}_{t_{0}}(A)>0$, the agent's credence function should change to $\operatorname{Pr}_{t_{1}}(B)=\operatorname{Pr}_{t_{0}}(B \mid A)$ for all $B \in \mathcal{A}$.

Now we are in a position to specify doxastic disagreement. We use ' $\operatorname{Pr}_{C_{a}}$ ' to refer to agent $a$ 's credence function. We say that two agents $a_{1}$ and $a_{2}$ are in doxastic disagreement with respect to a proposition $A$ iff $\operatorname{Pr}_{C_{a_{1}}}(A) \neq \operatorname{Pr}_{C_{a_{2}}}(A)$. And they are in doxastic disagreement iff there is one such proposition. In addition, a group (of agents) $G$ is in doxastic disagreement with respect to $A$ iff there are members $a_{1}$ and $a_{2}$ of $G$ who are in doxastic disagreement with respect to $A$. And the group is in doxastic disagreement iff there is one such proposition.

\subsection{Aggregating Credences Within The Standard Framework}

We presuppose that adequate rules for how to revise one's credences in the light of doxastic disagreement aggregate the credence functions of the agents involved to one new (aggregated) credence function. Henceforth, we call such rules aggregation rules. We use 'AR $\left.\operatorname{Pr}_{C_{a_{1}}}, \ldots, \operatorname{Pr}_{C_{a_{n}}}\right]$ ' to refer to the new credence function of the group of agents $G=\left\{a_{1}, \ldots, a_{n}\right\}$ that results from applying an aggregation rule $A R$. One requirement on such an aggregation rule is that if $\operatorname{Pr}_{C_{a_{1}}}, \ldots, \operatorname{Pr}_{C_{a_{n}}}$ is a rational credence function, then $A R\left[\operatorname{Pr}_{C_{a_{1}}}, \ldots, \operatorname{Pr}_{C_{a_{n}}}\right]$ is a rational credence function too. Accordingly, ' $A R\left[\operatorname{Pr}_{C_{a_{1}}}, \ldots, \operatorname{Pr}_{C_{a_{n}}}\right](A)$ ' denotes the new (rational) credence of the agents in proposition $A$. This setting presupposes that the agents not only learn that they disagree with respect to some proposition, but that the agents learn each others' credence functions. Next, let us introduce some widely accepted presuppositions concerning aggregation rules.

\footnotetext{
${ }^{1}$ As a concession to simplicity, we restrict the discussion to strict conditionalization.
} 
First, following Wagner (2010: 336-7) it is presupposed that one may use the same (adequate) aggregation rule in the following cases: First, an agent revises her credences in the light of doxastic disagreement in a group of which she is not a member. For example, an agent is interested in whether her skin anomaly is cancerous. She is not an expert but visits a group of dermatologists to solicit their expert opinions. Unfortunately, these experts have different credences with respect to whether her skin anomaly is cancerous. Accordingly, she needs an aggregation rule that aggregates the credences of the experts to form her own credence in that proposition. Second, an agent revises her credences in the light of doxastic disagreement in a group of which she is a member. For example, take the described skin anomaly example with the difference that now the agent is a dermatologist who consults her colleagues. Accordingly, she needs an aggregation rule that aggregates the credences of the other experts with her own credences. Third, a group is in doxastic disagreement and as a group they have to form an epistemic compromise. Even if the members of the group are not required to revise their (individual) credences, they are certainly required to agree on an epistemic compromise that respects each others' credences. For example, the dermatologists have to form an epistemic compromise with respect to whether her skin anomaly is cancerous, in order to make a joint decision (i.e. group decision) on whether to surgically remove the skin anomaly (imagine, e.g., they are jointly liable in the case of a wrong decision)..$^{2}$ Accordingly, the members of the group need an aggregation rule that aggregates their credences to form an epistemic compromise.

Second, one can distinguish levels of expertise in a coarse-grained way: experts, fools, and peers. ${ }^{3}$ One can also distinguish level of expertise in a more fine-grained way. We follow a typical idealising presupposition and assume that one can assign to each member $a_{i}$ of a group $G=\left\{a_{1}, \ldots, a_{n}\right\}$ a precise weight $w_{i}^{G}$ (of expertise) within this group. This weight reflects the level of relative competence of an agent within a group. The sum of the weights of all agents of a group equals one (i.e., $\sum_{i=1}^{n} w_{i}^{G}=1$ ). As it is standard, we also assume that an agent's weight applies for the whole algebra of propositions. The level of relative competence of an agent within a group

\footnotetext{
${ }^{2}$ The epistemic compromise of the group need not be interpreted as an epistemic state in the sense of a mental state. One might rather interpret it as a kind of disposition to act.

${ }^{3}$ The definition of peerhood, respectively an approach to how to assign different weights to the opinions of epistemic agents, is very problematic. In their careful and valuable discussion of the equal weight view, Jehle and Fitelson suggest that "two agents, $a_{1}$ and $a_{2}$, are epistemic peers regarding a proposition $A$ : that is, [...] $a_{1}$ and $a_{2}$ are equally competent, equally impartial, and equally able to evaluate and assess the relevant evidence regarding $A$ " (Jehle and Fitelson 2009: 280; notation adapted). Even though this is not a completely satisfying definition and it does not give us exact weights for all agents involved in a doxastic disagreement, this characterization of peerhood belongs among to the best we have. However, for Bayesians the definition of peerhood is even more problematic: On the one hand many Bayesians hold that all a priori credence functions are equally acceptable. According to Hajèk (2011), e.g., "Orthodox Bayesians in the style of de Finetti recognize no rational constraints on subjective probabilities beyond conformity to the probability calculus, and a rule for updating probabilities in the face of new evidence, known as conditioning." Thus, all probabilistic agents should be deemed equally competent and therefore all probabilistic agents should treat each other as peers with respect to every proposition. If this is correct, one wonders, couldn't we construct a justification of objective Bayesianism à la Williamson (2010) on basis of this assumption: before receiving any evidence we should consider all possible agents as peers independently of which credence function they chose. Then, if we come to a joint credence function with all possible probabilistic agents we end up with the "objective degree of belief that every agent should have". Finally we update these objective credences "in the face of new evidence". On the other hand some probabilistic measures assume that from the point of view of the individual probabilistic agent all other probabilistic agents are less competent. For example, according Greaves and Wallace (2006) a credence function is rational iff it maximizes expected cognitive (epistemic) utility. However, if this is true, why should we update our credences in the light of doxastic disagreement, if they already maximize expected utility?
} 
depends on her absolute or, respectively, unrelativized level of competence and the level of absolute competence of the other members of the group. Suppose for each member $a_{i}$ of a group $G=\left\{a_{1}, \ldots, a_{n}\right\}$ one quantifies her level of absolute competence with some number $c\left(a_{i}\right) \in \mathbb{R}^{+}$. Then one can calculate the weight $w_{i}^{G}$ by the following formula: $w_{i}^{G}=\frac{c\left(a_{i}\right)}{\sum_{j=1}^{n} c\left(a_{j}\right)}$. It is noteworthy that our assumption that $\sum_{i=1}^{n} w_{i}^{G}=1$ excludes cases where for all agents $a_{i}: c\left(a_{i}\right)=0$. In this paper we presuppose that the agents involved know each others' level of expertise; all this is as standard in the literature. Weights of agents will play a prominent role in Subsection 2.2.2.

Third, for simplicity we presuppose for a start that agents involved in a doxastic disagreement share the same evidence. This is an idealization that we do not encounter in real life. We readdress this issue in Section 2.3.

\subsubsection{Normative Requirements}

In order to provide an aggregation rule, a number of normative requirements have been suggested that any adequate aggregation rule should satisfy. In the following we discuss the most prominent requirements. Let us start with the Irrelevance of Alternatives (IA) requirement:

(IA) If a group of agents $G=\left\{a_{1}, \ldots, a_{n}\right\}$ aggregates their old credence functions $\operatorname{Pr}_{C_{a_{1}}}^{\text {old }}, \ldots, \operatorname{Pr}_{C_{a_{n}}}^{\text {old }}$, then their aggregated credence in a proposition $A$ depends only on $\operatorname{Pr}_{C_{a_{1}}}^{\text {old }}(A), \ldots, \operatorname{Pr}_{C_{a_{n}}}^{\text {old }}(A){ }^{4}$

That is, there is some function $f$ such that: $A R\left[\operatorname{Pr}_{C_{a_{1}}}^{\text {old }}, \ldots, \operatorname{Pr}_{C_{a_{n}}}^{\text {old }}\right](A)=f\left(\operatorname{Pr}_{C_{a_{1}}}^{\text {old }}(A), \ldots, \operatorname{Pr}_{C_{a_{n}}}^{\text {old }}(A)\right)$.

(IA) excludes that the agents' aggregated credence in a proposition is influenced by the old credences in propositions other than the proposition in question. (IA) is a common requirement on aggregation rules since McConway (1981) and Wagner (1982). Its attractiveness is due to the fact that it makes calculating the aggregated credence in a proposition easy because one only has to consider the old credences in the proposition.

Another requirement, which is very influential, is the Convexity (C) requirement:

(C) If a group of agents $G=\left\{a_{1}, \ldots, a_{n}\right\}$ aggregates their old credence functions $\operatorname{Pr}_{C_{a_{1}}}^{\text {old }}, \ldots, \operatorname{Pr}_{C_{a_{n}}}^{\text {old }}$, then their aggregated credence in a proposition $A$ is greater or equal $\min \left\{\operatorname{Pr}_{C_{a_{i}}}^{\text {old }}(A): a_{i} \in G\right\}$ and smaller or equal $\max \left\{\operatorname{Pr}_{C_{a_{i}}}^{\text {old }}(A): a_{i} \in G\right\}$.

That is, $\min \left\{\operatorname{Pr}_{C_{a_{i}}}^{\text {old }}(A): a_{i} \in G\right\} \leq A R\left[\operatorname{Pr}_{C_{a_{1}}}^{\text {old }}, \ldots, \operatorname{Pr}_{C_{a_{n}}}^{\text {old }}\right](A) \leq \max \left\{\operatorname{Pr}_{C_{a_{i}}}^{\text {old }}(A): a_{i} \in G\right\}$.

The following consideration speaks in favor of (C): suppose an aggregation rule violates this requirement. Then it yields that the aggregated credence of the agents $a_{1}$ and $a_{2}$ in a proposition $A$ lies outside of the interval $\left[\operatorname{Pr}_{C_{a_{1}}}^{\text {old }}(A), \operatorname{Pr}_{C_{a_{2}}}^{\text {old }}(A)\right]$, imagine, e.g., $A R\left[\operatorname{Pr}_{C_{a_{1}}}, \ldots, \operatorname{Pr}_{C_{a_{n}}}\right](A)>$ $\operatorname{Pr}_{C_{a_{1}}}^{\text {old }}(A)>\operatorname{Pr}_{C_{a_{2}}}^{\text {old }}(A)$. Such a result would be counterintuitive, since the aggregation rule is intended to reconcile the individual credences. Even if one ignored the old credence of $a_{2}$ in $A$ by adopting $a_{1}$ 's old credence in $A$ qua aggregated credence in $A$, it would still be closer to $a_{2}$ 's old

\footnotetext{
${ }^{4}$ The name is due to Jehle and Fitelson (2009). According to Genest and Zideck (1986), it is called Strong Set-Wise Function Property by McConway (1981) and Strong Label Neutrality by Wagner (1982).
} 
credence in $A$ than the one which lies outside the interval. In addition, (C) entails the Unanimity (U) requirement, which is a very plausible: ${ }^{5}$

(U) If a group of agents $G=\left\{a_{1}, \ldots, a_{n}\right\}$ aggregates their old credence functions, $\operatorname{Pr}_{C_{a_{1}}}^{\text {old }}, \ldots, \operatorname{Pr}_{C_{a_{n}}}^{\text {old }}$, and their old credences in a proposition $A, \operatorname{Pr}_{C_{a_{1}}}^{\text {old }}(A), \ldots \operatorname{Pr}_{C_{a_{n}}}^{\text {old }}(A)$, equal $r$, then their aggregated credence in $A$ equals $r$ too.

That is, $A R\left[\operatorname{Pr}_{C_{a_{1}}}^{\text {old }}, \ldots, \operatorname{Pr}_{C_{a_{n}}}^{\text {old }}\right](A)=r$, if $\operatorname{Pr}_{C_{a_{i}}}^{\text {old }}(A)=r$, for all $a_{i} \in G=\left\{a_{1}, \ldots, a_{n}\right\}$.

Imagine that two agents agree on their old credences in a proposition. Then (U) requires that both keep their old credences in the proposition qua aggregated credence. Rules on how to revise one's credences in the light of doxastic disagreement are only meant to be used when agents are in doxastic disagreement with each other. They are superfluous when the agents agree.

Now let us introduce more sophisticated requirements. The most uncontroversial and at the same time most discussed of them is the Commutativity with Learning (CL) requirement:

(CL) If a group of agents $G=\left\{a_{1}, \ldots, a_{n}\right\}$ aggregates their old credence functions, $\operatorname{Pr}_{C_{a_{1}}}^{\text {old }}, \ldots, \operatorname{Pr}_{C_{a_{n}}}^{\text {old }}$, an adequate aggregation rule, $\mathrm{AR}$, is commutative with learning some proposition $E$ (the evidence) by strict conditionalization on $E .^{6}$

That is, $A R\left[\operatorname{Pr}_{C_{a_{1}}}(\cdot \mid E), \ldots, \operatorname{Pr}_{C_{a_{n}}}(\cdot \mid E)\right](A)=\frac{A R\left[\operatorname{Pr}_{C_{a_{1}}}(\cdot), \ldots, \operatorname{Pr}_{C_{a_{n}}}(\cdot)\right](A \cap E)}{A R\left[\operatorname{Pr}_{C_{a_{1}}}(\cdot), \ldots, \operatorname{Pr}_{C_{a_{n}}}(\cdot)\right](E)}$ for all propositions $E$ (with $\operatorname{Pr}_{C_{a_{i}}}(E)>0$ for all $a_{i} \in G=\left\{a_{1}, \ldots, a_{n}\right\}$ ).

This requirement is indispensable for, at least, the following two reasons: First, it guarantees that the time of aggregating credences plays no role. According to it, it is irrelevant whether one first aggregates credences and afterwards incorporates new evidence by strict conditionalization, or whether one incorporates new evidence first and afterwards aggregates credences (see, also, Jehle and Fitelson 2009: 286). If an aggregation rule does not satisfy (CL) this "might entice the subjects [or one of them] to delay disclosing their opinions until after the data is reported, so as to increase the relative weight of their respective distribution in the pool" (Genest and Zideck 1986: 118). In such a case, the aggregated credence function would not only be determined by the aggregation rule and the agents' credence functions, but also by when the disagreement is taken into account.

Second, suppose a group of agents forms an epistemic compromise. Then (CL) requires the group to agree on a joint credence function which will make them "make decisions that appear to an outsider like the decisions of a single Bayesian agent" (Wagner 2010: 339). Following Wagner (2010) and others, we want to judge the rationality of groups of agents by the same standards

\footnotetext{
${ }^{5}$ This requirement is discussed in Allarda, Comunian, and Renard (2012). Other authors discuss weaker unanimity requirements. For example, Wagner (2010) restricts this requirement to hold not for all propositions, but only for possible worlds: $A R\left[\operatorname{Pr}_{C_{a_{1}}}^{\text {old }}, \ldots, \operatorname{Pr}_{C_{a_{n}}}^{\text {old }}\right](w)=r$, if $\operatorname{Pr}_{C_{a_{i}}}^{\text {old }}(w)=r$, for all $a_{i} \in G$. For the results mentioned and presented in the present paper the difference between the weak and the strong unanimity requirement is irrelevant.

${ }^{6}$ The name of this requirement is inspired by Wagner (2010), who calls it Commutativity with Conditionalization. In addition, Wagner (2010) actually discusses a stronger requirement, according to which an adequate aggregation rule should be commutative with Jeffrey Conditionalization. For simplicity, we discuss the weaker requirement here.
} 
that we apply to individual agents. For this purpose, satisfying (CL) is necessary.

Another important requirement is the No Zero Preservation (No-ZP) requirement:

(No-ZP) If a group of agents $G=\left\{a_{1}, \ldots, a_{n}\right\}$ aggregates their old credence functions, $\operatorname{Pr}_{C_{a_{1}}}^{\text {old }}, \ldots, \operatorname{Pr}_{C_{a_{n}}}^{\text {old }}$, it is not the case that their aggregated credence in a proposition $A$ equals 0 , whenever one of the members of $G$ 's old credences in $A$ equals 0 .

That is, it is not the case that $A R\left[\operatorname{Pr}_{C_{a_{1}}}^{\text {old }}, \ldots, \operatorname{Pr}_{C_{a_{n}}}^{\text {old }}\right](A)=0$, whenever $\operatorname{Pr}_{C_{a_{i}}}^{\text {old }}(A)=0$ for at least one of the agents $a_{i} \in G$.

The satisfaction of (No-ZP) ensures that an agent is not required to adopt the aggregated credence 0 just because there is another agent who has credence 0 in that proposition. ${ }^{7}$ Imagine two agents have different credences in a proposition and one of the agents has credence 0 in this proposition. Then, according to the standard probabilistic betting interpretation of credences, this latter agent is willing to bet everything, including her life, on the negation of the proposition. Should the second agent be required to have a credence 0 in the proposition and, thus, of one in its negation as well? This would be implausible. The agent is not required to adopt a credence which commits her to bet her life. This argumentation supports the even stronger requirement that $A R\left[\operatorname{Pr}_{C_{a_{1}}}^{\text {old }}, \ldots, \operatorname{Pr}_{C_{a_{n}}}^{\text {old }}\right](A)>0$, whenever $\operatorname{Pr}_{C_{a_{i}}}^{\text {old }}(A)>0$ for at least one of the agents $a_{i} \in G$ with $w_{i}^{G}>0$. However, for the present purpose it suffices to work with the weaker requirement (No-ZP).

Finally, let us address the most controversial requirement, the Preservation of Independence (PI) requirement:

(PI) If a group of agents $G=\left\{a_{1}, \ldots, a_{n}\right\}$ aggregates their old credence functions, $\operatorname{Pr}_{C_{a_{1}}}^{\text {old }}, \ldots, \operatorname{Pr}_{C_{a_{n}}}^{\text {old }}$, then their aggregated credence function preserves initially-agreed-upon judgements of independence.

That is, $A R\left[\operatorname{Pr}_{C_{a_{1}}}^{\text {old }}, \ldots, \operatorname{Pr}_{C_{a_{n}}}^{\text {old }}\right](A \cap B)=A R\left[\operatorname{Pr}_{C_{a_{1}}}^{\text {old }}, \ldots, \operatorname{Pr}_{C_{a_{n}}}^{\text {old }}\right](A) \times A R\left[\operatorname{Pr}_{C_{a_{1}}}^{\text {old }}, \ldots, \operatorname{Pr}_{C_{a_{n}}}^{\text {old }}\right](B)$, if $\operatorname{Pr}_{C_{a_{i}}}^{\text {old }}(A \cap B)=\operatorname{Pr}_{C_{a_{i}}}^{\text {old }}(A) \times \operatorname{Pr}_{C_{a_{i}}}^{\text {old }}(B)$, for all $a_{i} \in G$.

According to (PI) (which is prominently supported by Laddaga 1977), any aggregation rule has to preserve initially-agreed-upon judgements of probabilistic independence. Thus, if two agents agree that two propositions are probabilistically independent, then they should keep agreeing about this. Jehle and Fitelson (2009), who are sympathetic to this requirement (even though they do not ultimately endorse it), remark that

from an epistemic point of view, assessments of (in)dependence can reflect evidential relationships induced by an agent's credence function (viz., Bayesian confirmation theory; see also Jeffrey (1987)). In such contexts, we think it would be undesirable for [an

\footnotetext{
${ }^{7}$ It is noteworthy that (No-ZP) is not the negation of the weak Zero Preservation Property, discussed in Genest and Zideck (1986). This latter requirement states that if all agents have credences 0 , then the aggregated credence is 0 too. This requirement is implied by (U). (No-ZP) is the negation of a strong zero preservation property, which requires that if one of the members of the group has credence 0 in a proposition, then all agents should adopt credence 0 . This strong zero preservation property is not implied by (U). Allarda, Comunian, and Renard (2012) discuss and defend a related requirement, the $0 / 1$-forcing property, which is the negation of our (No-ZP).
} 
aggregation rule] to undermine agreed-upon assessments of these important relations. (Jehle and Fitelson 2009: 283, emphasis in the original) ${ }^{8}$

Accordingly, agreement on (in)dependence judgements are equally as important as agreement with respect to credences. (U) requires that if two agents agree on their credences in a proposition, then an adequate aggregation rule should not require that they change their credences in that proposition. Similarly, (PI) requires that if two agents agree on the probabilistic independence of two propositions, then an adequate aggregation rule should not require that they change this judgment.

A number of philosophers argue that (PI) is implausible. In particular, Lehrer and Wagner (1983: 340) argue that "for a large class of probability assessment problems, there is neither a prior theoretical determination of independence nor even much interest in posterior observations that certain propositions are independent." In addition, the satisfaction of (PI) sometimes requires reversing initially-agreed-upon comparisons of credences (Lehrer and Wagner 1983, Genest and Wagner 1987). ${ }^{9}$ For example, all members of the group initially agree that proposition $A$ is more credible than proposition $B$, but after aggregating their credences they agree that $B$ is more credible. Thus, in the decision process it might be the case that initially all agents agree that $A$ is more credible than $B$ and that therefore they should opt for some specific action. However, after aggregating their credences in accordance with (PI) they suddenly take $B$ to be the more credible proposition and that therefore they should opt for some alternative action. This is certainly counterintuitive. Accordingly, today a number of epistemologists do not think that (PI) is a mandatory requirement on aggregation rules.

Unfortunately, it is not possible to simultaneously satisfy all these normative requirements, except in very limited cases. Satisfying some of them forces one to violate others. For example, Lehrer and Wagner (1983) show that (IA) and (PI) are not jointly satisfiable except dictatorially (i.e. by setting the weights $w_{i}^{G}$ at 0 for all but one agent). A consequence of the observations of Genest, McConway, and Schervish (1986) is that (CL) is incompatible with each of the following requirements: (IA), (C), (U),(PI), and (No-ZP), again except dictatorially. For a particular comprehensive overview of the relevant results see Genest and Zideck (1986). Instead of focusing on these incompatible requirements some philosophers have suggested specific aggregation rules.

\subsubsection{Aggregation Rules}

The core idea of the aggregation rules that can be found in the literature can be summarized by the slogan: split the difference (e.g. Jehle and Fitelson 2009). More specifically, in order to come up with an aggregation rule, it is suggested that we measure the distance, or difference, between the credences and meet somewhere in between the original credences. For example, suppose two

\footnotetext{
${ }^{8}$ To be precise, Jehle and Fitelson claim this for specific rules on how to revise one's credence in the light of peer disagreement, so-called equal weight rules. We return to these rules in section 2.2.3.

${ }^{9}$ Genest and Wagner (1987) refer in this context to Raiffa (1968: 231-233). Wagner (2010) provides an interesting suggestion of how to reconcile (PI) with the aggregation rule (AM) (see below), if (PI) is not required to hold for all propositions.
} 
agents $a_{1}$ and $a_{2}$ are in doxastic disagreement with respect to proposition $A$, then the aggregated credence in $A$ should be equally distanced from both agents' original credences in $A$. We want to allow for different weights associated with the different agents. Accordingly, we can specify the slogan by the following Proportional Distance/Difference requirement $(P \Delta)$ :

$(P \Delta)$ If a group of two agents $G=\left\{a_{1}, a_{2}\right\}$ aggregate their old credence functions, $\operatorname{Pr}_{C_{a_{1}}}^{\text {old }}$ and $\operatorname{Pr}_{C_{a_{2}}}^{\text {old }}$, then the difference between the aggregated credence function and their old credence functions is proportional to the weights assigned to both agents.

That is, $w_{1}^{G} \Delta\left[A R\left[\operatorname{Pr}_{C_{a_{1}}}^{\text {old }}, \operatorname{Pr}_{C_{a_{2}}}^{\text {old }}\right], \operatorname{Pr}_{C_{a_{1}}}^{\text {old }}\right]=w_{2}^{G} \Delta\left[A R\left[\operatorname{Pr}_{C_{a_{1}}}^{\text {old }}, \operatorname{Pr}_{C_{a_{2}}}^{\text {old }}\right], \operatorname{Pr}_{C_{a_{2}}}^{\text {old }}\right]$, whereas $\Delta$ is a measure of the distance between probability functions and $\sum_{i=1}^{2} w_{i}^{G}=1$.

In accordance with the splitting the difference slogan, two measures of the distance of probability functions are discussed in the literature: the Relative Entropy Measure and the Inverse Relative Entropy Measure. Both measures are defined on the atoms $\omega \in \Omega$ of the algebra $\mathcal{A}$ instead of the propositions in the algebra. The first measure is the Relative Entropy Measure, or the KullbackLeibler Divergence, $(\Delta \mathrm{RE})$ :

$(\Delta \mathbf{R E}) \Delta_{R E}\left[\operatorname{Pr}_{1}, \operatorname{Pr}_{2}\right]=\sum_{\omega \in \Omega} \log \left[\frac{\operatorname{Pr}_{1}(\omega)}{\operatorname{Pr}_{2}(\omega)}\right] \times \operatorname{Pr}_{1}(\omega)$.

$(\triangle \mathrm{RE})$ implies that the aggregated credence function can be calculated by taking the weighted arithmetic mean of the old credence functions (Abbas 2009). The corresponding rule is the Weighted Arithmetic Mean Rule (AM):

(AM) If a group of agents $G=\left\{a_{1}, \ldots, a_{n}\right\}$ aggregates their old credence functions, $\operatorname{Pr}_{C_{a_{1}}}^{\text {old }}, \ldots, \operatorname{Pr}_{C_{a_{n}}}^{\text {old }}$, then their aggregated credence function, $A M\left[\operatorname{Pr}_{C_{a_{1}}}^{\text {old }}, \ldots \operatorname{Pr}_{C_{a_{n}}}^{\text {old }}\right]$, can be calculated as follows:

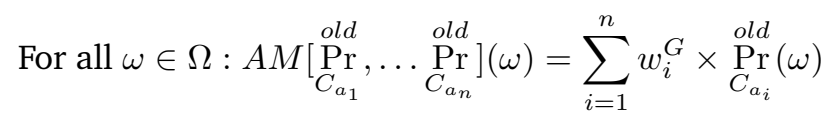

whereas $w_{i}^{G} \in \mathbb{R}^{+}, \sum_{i=1}^{n} w_{i}^{G}=1$.

$\Delta_{R E}$ is the most widely used measure for quantifying the distance between probability functions. However, it is not a distance measure in the strict sense of the word because it is not symmetric. If one employs the following Inverse Relative Entropy Measure ( $\Delta \mathrm{IRE}$ ) one may get different results on the distance:

( $\triangle$ IRE) $\Delta_{I R E}\left[\operatorname{Pr}_{1}, \operatorname{Pr}_{2}\right]=\sum_{\omega \in \Omega} \log \left[\frac{\operatorname{Pr}_{2}(\omega)}{\operatorname{Pr}_{1}(\omega)}\right] \times \operatorname{Pr}_{2}(\omega)$.

Measuring the distance by $\Delta_{I R E}$ implies that the new credence function can be calculated by taking the normalized weighted geometric mean of the old credence functions (Abbas 2009). The corresponding rule is the Normalized Weighted Geometric Mean Rule (GM):

(GM) If a group of agents $G=\left\{a_{1}, \ldots, a_{n}\right\}$ aggregates their old credence functions, $\operatorname{Pr}_{C_{a_{1}}}^{\text {old }}, \ldots, \operatorname{Pr}_{C_{a_{n}}}^{\text {old }}$, then their aggregated credence function, $G M\left[\operatorname{Pr}_{C_{a_{1}}}^{\text {old }}, \ldots \operatorname{Pr}_{C_{a_{n}}}^{\text {old }}\right]$, can be calculated as follows:

$$
\text { For all } \omega \in \Omega: G M\left[\stackrel{\text { old }}{\operatorname{Pr}}, \ldots \underset{C_{a_{1}}}{\operatorname{old}} \underset{C_{a_{n}}}{\operatorname{pr}}\right](\omega)=\frac{\prod_{i=1}^{n} \operatorname{Pr}_{C_{a_{i}}}^{\text {old }}(\omega)^{w_{i}^{G}}}{\sum_{\omega \in \Omega} \prod_{i=1}^{n} \operatorname{Pr}_{C_{a_{i}}}^{\text {old }}(\omega)^{w_{i}^{G}}}
$$


whereas $w_{i}^{G} \in \mathbb{R}^{+}, \sum_{i=1}^{n} w_{i}^{G}=1$.

Both aggregation rules satisfy $(\mathrm{P} \Delta)$. For comparing them, it is worthwhile to investigate which of the above normative requirements are satisfied by these aggregation rules:

\begin{tabular}{ccccccc} 
Aggregation Rule & (IA) & (C) & (U) & (CL) & (No-ZP) & (PI) \\
\hline$(\mathrm{AM})$ & Yes & Yes & Yes & No & Yes & No \\
$(\mathrm{GM})$ & No & No & No & Yes & No & No \\
& & & & & &
\end{tabular}

Table 1 demonstrates that both aggregation rules are unacceptable from a philosophical point of view. On the one hand, (GM) does not satisfy any of the requirements except (CL). In particular, neither the intuitively plausible requirements (IA), (C), and (U) nor the indispensable requirement (No-ZP) are satisfied. That (GM) satisfies the important requirement (CL) is not a sufficient reason for accepting it. (The dissatisfaction of (IA), (C), (U), and (No-ZP) by $G M$ follows trivially from the definition of $G M$. For the other results see Genest and Zideck (1986: 118-9), who give a comprehensive overview over the literature). (AM), on the other hand, satisfies most requirements, but not the indispensable (PI) and (CL) (again we refer to Genest and Zideck (1986: 118-9) for the relevant results), which is a sufficient reason for rejecting it. In the light of this balance sheet many philosophers find both rules, (AM) and (GM), unacceptable and are searching for alternatives.

\subsubsection{Jehle and Fitelson's Approach}

Recently, Jehle and Fitelson (2009) have suggested a new approach for dealing with doxastic disagreement. They focus on cases of doxastic disagreement with respect to so-called peerpropositions. For Jehle and Fitelson (2009: 280) a proposition is a peer-proposition for two agents if both are "equally competent, equally impartial, and equally able to evaluate and assess the relevant evidence regarding" this proposition. Since Jehle and Fitelson consider only agents that are peers (with respect to the proposition in question), they do not assign different weights to the agents' (with respect to this proposition). Jehle and Fitelson, however, do not subscribe to the simplifying assumption that the agents are peers with respect to all propositions in the algebra under consideration. Therefore, they do not subscribe to the requirement that an aggregation rule should lead the agents to agreement on every proposition. Aware of many of the problems discussed in Section 2.2, Jehle and Fitelson (2009: 283-4, notation adapted) reject the idea that when agents "discover they disagree regarding a peer-proposition $A$, they should both adopt a new credence for $A$ that is the straight average of their initial credences for $A$." As a possible replacement for this Straight Average Rule, Jehle and Fitelson suggest, but do not endorse, two new rules on how to deal with doxastic disagreement. In the following we introduce these rules and argue that they are inadequate. 
First, let us introduce the common core of the two rules suggested by Jehle and Fitelson (2009): Approximate Straight Averaging + Minimal Change (ASAMC) and Approximate Equality (AE). (ASAMC) is the following requirement:

(ASAMC) "If $a_{1}$ and $a_{2}$ find themselves disagreeing about a peer-proposition $A$ at $t_{0}$, then they should each update on $A$ so that:

$$
\underset{C_{a_{i}}}{\operatorname{nrw}}(A) \approx \frac{\operatorname{Pr}_{C_{a_{1}}}^{\text {old }}(A)+\operatorname{Pr}_{C_{a_{2}}}^{\text {old }}(A)}{2}
$$

where $\operatorname{Pr}_{C_{a_{i}}}^{\text {new }}(A)$ is strictly between $\operatorname{Pr}_{C_{a_{1}}}^{\text {old }}(A)$ and $\operatorname{Pr}_{C_{a_{2}}}^{\text {old }}(A)$ and where the update is done in a way that satisfies $(\mathrm{P})$ [which requires that the new credences obey the probability calculus] and (C) [our (CL)]. If additional changes must be made (on non-peer-propositions) to $\operatorname{Pr}_{C_{a_{1}}}^{\text {old }}(\cdot)$ and/or $\operatorname{Pr}_{C_{a_{2}}}^{\text {old }}(\cdot)$ in order to ensure satisfaction of (P) and (C), then the other changes should be made so as to minimize the distance of $\operatorname{Pr}_{C_{a_{1}}}^{\text {new }}(\cdot)$ and $\operatorname{Pr} n e w_{C_{a_{2}}}(\cdot)$ from the initial distribution(s) $\operatorname{Pr}_{C_{a_{1}}}^{\text {old }}(\cdot)$ and $\operatorname{Pr}_{C_{a_{2}}}^{\text {old }}(\cdot)$, while maintaining satisfaction of (P) and (C)." (Jehle and Fitelson 2009: 287-8, notation adapted).

The requirement that $\operatorname{Pr}_{C_{a_{i}}}^{\text {new }}(A) \approx \frac{\operatorname{Pr}_{C_{a_{1}}}^{\text {old }}(A)+\operatorname{Pr}_{C_{a_{2}}}^{\text {old }}(A)}{2}$ says that the new credence(s) in a proposition $A$ should approximate the straight average of their old credences in that proposition. Jehle and Fitelson suggest approximation only, since equality leads to implausible results (see Jehle and Fitelson 2009: 284-7). In addition, Jehle and Fitelson "impose this strict between-ness requirement so as to rule out dictatorial updates, which revert to one of the two initial assignments" and they "assume that $a \approx b$ iff $|a-b|<\epsilon$, for some 'small' $\epsilon>0$ " (Jehle and Fitelson 2009: en. 14).

The satisfaction of (ASAMC) does not guarantee that the new credences are "close to each other" (Jehle and Fitelson 2009: 288). If a rule for how to revise one's credences in the light of doxastic disagreement allows that the credences of two peers in peer-propositions end up not being close to each other, then the entire discussion on such rules is superfluous. The idea behind debates about how to resolve doxastic disagreement is that agents end up agreeing, at least approximately, with each other. That is why Jehle and Fitelson add the following requirement to (ASAMC), which we call Approximate Equality (AE):

(AE) $\operatorname{Pr}_{C_{a_{1}}}^{n e w}(A) \approx \operatorname{Pr}_{C_{a_{2}}}^{n e w}(A)$ (Jehle and Fitelson 2009: 288).

(AE) ensures that the new credences of agents $a_{1}$ and $a_{2}$ in peer-proposition $A$ are approximately equal.

There are two ways in which the agents may satisfy (ASAMC) and (AE): first, they end up with different credences in $A$ or, second, they end up with equal credences, but one agent might change her credences more than the other agent (Jehle and Fitelson 2009: 288-9). Accordingly, Jehle and Fitelson suggest two different requirements that are added to the common core and distinguish 
the first rule from the second: the Agreement (A) requirement and what we call theRemaining Inequality (RI) requirement.

(A) $\operatorname{Pr}_{C_{a_{1}}}^{\text {new }}(A)=\operatorname{Pr}_{C_{a_{2}}}^{\text {new }}(A)$, where "the consensus value [...] will (sometimes) have to be closer to one of the initial credences than it is to the other. As a result, one of the peers will have to make a larger change [...] to their initial credence than the other peer does" (Jehle and Fitelson 2009: 288-9, emphasis in the original).

(RI) $\operatorname{Pr}_{C_{a_{1}}}^{\text {new }}(A) \approx \operatorname{Pr}_{C_{a_{2}}}^{\text {new }}(A)$, where both credences "may remain unequal [but are] equally far from the midpoint between the initial credences", furthermore, it allows that credences in peer-propositions end up being different (Jehle and Fitelson 2009: 289, emphasis in the original).

Jehle and Fitelson's first rule consists of the common core, (ASAMC) and (AE), plus (A). Their second rule consists of the common core, (ASAMC) and (AE), plus (RI).

We begin with specific criticism of both rules. We end with a general criticism of the common core of both rules. The first rule, which consists of (ASAMC), (AE), and (A), allows for unequal treatment of both peers (Jehle and Fitelson 2009: 289). Strictly speaking, it does not even require that the respective credences in peer-propositions are equally taken into consideration in cases whenever it is possible. Therefore, it is not required that the new credence in a peer-proposition is "equally far from the midpoint" whenever it is possible. More generally, often it will be the case that there is more than one credence that satisfies (ASAMC), (AE), and (A). This makes the new credence adopted on the first rule somewhat arbitrary. ${ }^{10}$

The second rule, which consists of (ASAMC), (AE), and (RI), allows that two agents end up with different credences with respect to a peer-proposition. A first criticism is that it is unclear why agents should revise their credences in the light of doxastic disagreement in the first place if the agents end up disagreeing with respect to a peer proposition after all. Even worse, the second rule might require the agents to apply it again and again since the agents keep on disagreeing after the application of the rule. ${ }^{11}$ A second criticism is that this rule does not require the agents to agree on a specific credence in a proposition if they can agree without violating one of Jehle and Fitelson's other requirements. A third criticism is that this second rule does not help in cases where a group has to form an epistemic compromise for a joint decision. Even if two agents have the same utility function and approximate credences, it does not guarantee that they will come to the same decision concerning the different options available. The fourth and final criticism of the second rule is that it is not straightforwardly generalizable to cases involving more than two agents. For example, imagine a case of peer disagreement involving three agents and that the third agent's credence in the peer-proposition in question equals the straight average of the first

\footnotetext{
${ }^{10}$ One might even argue that in the light of this observation, Jehle and Fitelson (2009) do not even suggest a proper aggregation rule, but rather a further normative requirement on aggregation rules. We just want to flag this issue, without discussing it further.

${ }^{11}$ The most intuitive approach to resolving this problem is to redefine doxastic disagreement. In particular, one could circumvent this objection by defining that two agents $a_{1}$ and $a_{2}$ are in doxastic disagreement with respect to some proposition $A$ iff $\operatorname{Pr}_{C_{a_{1}}}(A) \not \approx \operatorname{Pr}_{C_{a_{2}}}(A)$.
} 
two agents' credences in this proposition. According to the rule, the three credences in the peerproposition should be approximately equal and they should approximate the straight average of the credences, i.e., the credence of the third agent. However, due to (RI) the second rule requires that all credences are equally far from the midpoint. This latter requirement cannot be satisfied in the present example, since the credence in the peer-proposition of the third agent is already the midpoint of the first and the second agent's credences in this proposition.

Finally, we want to add one general criticism of (ASAMC) itself. In particular, we argue that (ASAMC) is not feasible if we assume that every proposition is a peer-proposition. First note that (ASAMC) imposes the strict between-ness requirement that the new credence should be strictly in-between the agents' old credences. Given the assumption that every proposition is a peerproposition this requirement is slightly stronger than our requirement (C). Second, (ASAMC) requires that peer updating is commutative with learning by strict conditionalization, our (CL). However, as already said, one consequence of the observations of Genest, McConway, and Schervish (1986) (see also Wagner 2010) is that (C) and (CL) are not generally jointly satisfiable. Thus, if we presuppose that every proposition is a peer-proposition, their strict between-ness requirement and their commutativity requirement are not in general compatible.

\subsection{Further Problems}

Subsection 2.2 shows that according to the state of the art there is no adequate aggregation rule within the standard probabilistic framework for modeling epistemic states. This subsection demonstrates, in addition, that there are cases of epistemic disagreement that are not cases of doxastic disagreement and cannot be modeled adequately within this framework.

Consider the following examples: suppose, first, theoretical physicist $a_{1}$ considers experimental physicist $a_{2}$ an expert with respect to gathering evidence, but a fool with respect to the confirmational import of the respective evidence. Accordingly, $a_{1}$ would like to assume $a_{2}$ 's evidence, but to ignore $a_{2}$ 's judgement of the confirmational import of the evidence. Or suppose, second, experimental physicist $a_{3}$ considers theoretical physicist $a_{4}$ a fool with respect to gathering evidence, but an expert with respect to the confirmational import of the respective evidence. Accordingly, $a_{3}$ would like to ignore what agent $a_{4}$ accepts as evidence, but to assume $a_{4}$ 's judgement of the confirmational import of $a_{3}$ 's evidence. Both examples demonstrate that there are cases of epistemic disagreement that cannot be understood as cases of doxastic disagreement. In addition, they indicate that the doxastic disagreement of two agents can be based on disagreement with respect to two aspects of their epistemic state: first, they might disagree on the evidence on which they base their credences. We call this form of disagreement evidential disagreement. Second, they might disagree on the confirmational import of their evidence with respect to a proposition in question. We call this form of disagreement confirmational disagreement. Finally, it might be the case that the doxastic disagreement of two agents is based on evidential and confirmational disagreement. That is the case if they have different evidence and they judge the confirmational import of this 
evidence differently with respect to the proposition in question. However, these cases of epistemic disagreement cannot be reduced to cases of doxastic disagreement since two agents might be in evidential and confirmational disagreement without being in doxastic disagreement. That is for example the case if they have a different evidence and they judge the confirmational import of their evidence differently, but accidentally end up with equal credences in the proposition in question.

\section{An Alternative Probabilistic Framework}

\subsection{Modeling Doxastic Disagreement}

The preceding sections demonstrate that the standard probabilistic framework for modeling epistemic states and doxastic disagreement has two problems. First, it is not possible to frame an adequate aggregation rule within the standard probabilistic framework. Second, not all forms of epistemic disagreement can be modeled within this framework. In particular, in this framework it is impossible to adequately model evidential and confirmational disagreement. In the light of the problems, we suggest an alternative probabilistic framework for modeling epistemic states, one which allows us to model all forms of epistemic disagreement: doxastic, evidential, and confirmational disagreement. The alternative probabilistic framework presupposes the following:

Pluralistic Bayesianism First, a (rational) agent's epistemic state is best represented by (an ordered pair consisting of) her (rational) confirmation commitments (i.e. the judgements of the confirmational import of the evidence, which capture how agents justify their credences) and her total evidence. Second, the agent's (rational) credences equal her (rational) confirmation commitments conditional on the evidence. And, finally, third, (rational) credences and (rational) confirmation commitments obey the probability calculus.

That is, we propose (i) to represent a (rational) agent's $a_{1}$ epistemic state, $E S_{a_{1}}=\left\langle\operatorname{Pr}_{\text {conf } f_{a_{1}}}, E\right\rangle$, by her confirmation commitments, $P r_{\text {conf } f_{a_{1}}}$, and her total evidence, $E$, (ii) that $\operatorname{Pr}_{C_{a_{1}}}(A)=$ $\operatorname{Pr}_{\text {conf }_{a_{1}}}(A \mid E)$, and (iii) that $\operatorname{Pr}_{C_{a_{1}}}$ and $\operatorname{Pr}_{\text {conf } f_{a_{1}}}$ obey the probability calculus.

This framework is endorsed by a number of philosophers, independently of the epistemological problems in the context of doxastic disagreement. Levi (1980) and, especially, Lange (1999) argue that adopting Pluralistic Bayesianism is important for understanding the proper epistemic role of conditionalization within probabilistic epistemology. Similarly, AUTHORS argues that an adequate theory of confirmation must presuppose Pluralistic Bayesianism. In the following we investigate whether this new framework helps in dealing with doxastic disagreement. First, we demonstrate that within this framework we can adequately model cases of epistemic disagreement that could not be modeled within the standard probabilistic framework.

According to the first example, theoretical physicist $a_{1}$ considers experimental physicist $a_{2}$ an expert with respect to gather evidence, but a fool with respect to the confirmational import of the respective evidence. Accordingly, $a_{1}$ would like to add agent $a_{2}$ 's evidence to her own, but to 
ignore $a_{2}$ 's judgement of the confirmational import of the evidence. Accordingly, if $a_{1}$ 's old epistemic state is $E S_{a_{1}}^{\text {old }}=\left\langle\operatorname{Pr}_{\text {conf } a_{1}}, E_{1}\right\rangle$ and $a_{2}$ 's old epistemic state is $E S_{a_{2}}^{\text {old }}=\left\langle\operatorname{Pr}_{\text {conf } a_{a_{2}}}, E_{2}\right\rangle$, then $a_{1}$ 's new epistemic state in the light of this disagreement is $E S_{a_{1}}^{\text {new }}=\left\langle\operatorname{Pr}_{\text {conf }}^{\text {old }} f_{a_{1}}, E_{1} \cap E_{2}\right\rangle$.

According to the second example, experimental physicist $a_{3}$ considers theoretical physicist $a_{4}$ a fool with respect to gathering evidence, but an expert with respect to the confirmational import of the respective evidence. Accordingly, $a_{3}$ would like to ignore what agent $a_{4}$ accepts as evidence, but to assume $a_{4}$ 's judgement of the confirmational import of the evidence. Accordingly, if $E S_{a_{1}}^{\text {old }}=\left\langle\operatorname{Pr}_{\text {conf } a_{1}}, E_{1}\right\rangle$ and $E S_{a_{2}}^{\text {old }}=\left\langle\operatorname{Pr}_{\text {conf } a_{2}}, E_{2}\right\rangle$, then $E S_{a_{1}}^{\text {new }}=\left\langle\operatorname{Pr}_{\text {conf } a_{a_{2}}}, E_{1}\right\rangle$.

These cases of epistemic disagreement are extreme cases in which the other agent's confirmation commitments are adopted or ignored, and in which the agent's evidence is adopted or ignored. It displays the versatility of this new framework, but it does not answer the question of how to (rationally) revise one's epistemic state in the light of doxastic disagreement when one shares (total) evidence. Now let us consider whether one can make progress in answering this question within this new framework.

\subsection{Splitting the Difference, Revised}

Suppose two agents $a_{1}$ and $a_{2}$ are in doxastic disagreement in the light of shared (total) evidence $E$. Thus, even though $E$ captures both agents' evidence they end up with different credences $\operatorname{Pr}_{C_{a_{1}}}(A)$ and $\operatorname{Pr}_{C_{a_{2}}}(A)$ with respect to proposition $A$. Given our framework, this is due to their different confirmation commitments $\operatorname{Pr}_{c o n f_{a_{1}}}(A \mid E)$ and $\operatorname{Pr}_{c o n f_{a_{2}}}(A \mid E)$, which depend on $\operatorname{Pr}_{\text {conf } a_{a_{1}}}(A \cap E), \operatorname{Pr}_{c o n f_{a_{1}}}(E)$, and $\operatorname{Pr}_{\text {conf } f_{a_{2}}}(A \cap E)$, and $\operatorname{Pr}_{\text {conf } f_{a_{2}}}(E)$. Accordingly, a natural proposal is to apply the aggregation rules introduced in Section 2.2 to confirmation commitments instead of credences. In the following we propose a revised aggregation rule (AM*), the Weighted Arithmetic Mean Rule, Revised, which corresponds to (AM), and argue that it adequately answers the question of how to (rationally) revise one's epistemic state in the light of doxastic disagreement.

Suppose the agents of a group all share the same evidence but disagree in their confirmation commitments and based on this in their credences towards some proposition. Following our proposal they aggregate their confirmation commitments to resolve their doxastic disagreement. The aggregation rule we want to propose for this purpose is the following:

(AM*) If a group of agents $G=\left\{a_{1}, \ldots, a_{n}\right\}$ aggregates their old epistemic states, $E S_{a_{1}}^{\text {old }}, \ldots, E S_{a_{n}}^{\text {old }}$, in the light of shared total evidence $E$, then their aggregated epistemic state, $A M^{*}\left[E S_{a_{1}}^{\text {old }}, \ldots, E S_{a_{n}}^{\text {old }}\right]$, is defined as follows:

$$
A M^{*}\left[E S_{a_{1}}^{\text {old }}, \ldots, E S_{a_{n}}^{\text {old }}\right]=\left\langle A M\left[\underset{\operatorname{conf}{a_{1}}_{1}}{\operatorname{Pr}}, \ldots \underset{\operatorname{conf} f_{a_{n}}}{\operatorname{Pr}}\right], E\right\rangle
$$


and

$$
A M\left[\underset{\operatorname{conf} f_{a_{1}}}{\operatorname{Pr}}, \ldots \operatorname{conf}_{a_{n}}^{\operatorname{Pr}}\right](\omega)=\sum_{i=1}^{n} w_{i}^{G} \times \underset{\operatorname{conf} f_{a_{i}}}{\operatorname{Pr}}(\omega)
$$

whereas $w_{i}^{G} \in \mathbb{R}^{+}$and $\sum_{i=1}^{n} w_{i}^{G}=1$.

For comparison, we also consider a revised aggregation rule that corresponds to (GM), the Normalized Weighted Geometric Mean Rule, Revised (GM*):

(GM*) If a group of agents $G=\left\{a_{1}, \ldots, a_{n}\right\}$ aggregates their old epistemic states, $E S_{a_{1}}^{\text {old }}, \ldots, E S_{a_{n}}^{\text {old }}$, in the light of shared total evidence $E$, then their aggregated epistemic state, $G M^{*}\left[E S_{a_{1}}^{\text {old }}, \ldots, E S_{a_{n}}^{\text {old }}\right]$, is defined as follows:

$$
G M^{*}\left[E S_{a_{1}}^{\text {old }}, \ldots, E S_{a_{n}}^{\text {old }}\right]=\left\langle G M\left[\underset{\operatorname{conf} f_{a_{1}}}{\operatorname{Pr}}, \ldots \underset{\operatorname{conf}{a_{n}}_{n}}{\operatorname{Pr}}\right], E\right\rangle
$$

and

$$
G M\left[\operatorname{Pr}_{\operatorname{Pon} f_{a_{1}}}, \ldots \operatorname{Pr}_{\operatorname{conf} a_{n}}\right](\omega)=\frac{\prod_{i=1}^{n} \operatorname{Pr}_{\operatorname{conf} a_{i}}(\omega)^{w_{i}^{G}}}{\sum_{\omega \in \Omega} \prod_{i=1}^{n} \operatorname{Pr}_{\operatorname{conf} a_{i}}(\omega)^{w_{i}^{G}}}
$$

whereas $w_{i}^{G} \in \mathbb{R}^{+}$and $\sum_{i=1}^{n} w_{i}^{G}=1$.

In the following, we show that $\left(\mathrm{AM}^{*}\right)$ satisfies all our normative requirements except $(\mathrm{IA})$ and (PI) and argue that the non-satisfaction of these two requirements is no epistemic deficit. However, keep in mind that we presuppose that the agents all share the same evidence. The claim that $\left(\mathrm{AM}^{*}\right)$ satisfies all normative requirements except (IA) and (PI) depends on this background assumption.

First, consider requirement (IA). It requires that the aggregated credence in a proposition is a function of the agent's old credences in that proposition. Obviously, aggregation rule (GM*) does not satisfy this requirement. Just suppose two agents $a_{1}$ and $a_{2}$ received only the trivial evidence $E \cup \neg E$ and therefore $\operatorname{Pr}_{C_{a_{i}}}=\operatorname{Pr}_{\text {conf } f_{a_{i}}}$ for both of them. We already know from Section 2.2.2 that (GM) does not satisfy (IA), if we apply it to credence functions $\operatorname{Pr}_{C_{a_{1}}}$ and $\operatorname{Pr}_{C_{a_{2}}}$. Since we assumed that the agents received only the trivial evidence $E \cup \neg E$ and $\operatorname{Pr}_{C_{a_{i}}}=\operatorname{Pr}_{c o n f_{a_{i}}}$ for both agents, this proves that (GM*) does not satisfy (IA). It is not so trivial to show that (AM*) does not satisfy (IA). ${ }^{12}$ Note that, according to the picture we are promoting, the agents' credences in

\footnotetext{
${ }^{12}$ Proof: In order show that $\left(\mathrm{AM}^{*}\right)$ does not satisfy (IA) we have to show that the aggregated credence is not a function of the credence of the individual agents. For this purpose suppose that $\operatorname{Pr}_{C_{a_{1}}}(A)=\operatorname{Pr}_{\text {conf } a_{a_{1}}}(A \mid E)=\frac{1}{2}$ and $\operatorname{Pr}_{C_{a_{2}}}(B)=\operatorname{Pr}_{\text {conf } f_{2}}(A \mid E)=\frac{1}{4}$ and $w_{1}=w_{2}=\frac{1}{2}$. In Scenario $I$ suppose $(i) \operatorname{Pr}_{\text {conf } a_{1}}(E)=\frac{1}{2}$ and $\operatorname{Pr}_{\text {conf } a_{a_{2}}}(E)=\frac{1}{4}$, (ii) $\operatorname{Pr}_{c o n f_{a_{1}}}(A \cap E)=\frac{1}{4}$ and $\operatorname{Pr}_{c o n f_{a_{2}}}(A \cap E)=\frac{1}{16}$. Therefore, the new credence of the agent's equals the conditional aggregated credences $A M\left[\operatorname{Pr}_{c o n f_{a_{1}}}, \operatorname{Pr}_{c o n f_{a_{2}}}\right](A \mid E)=\frac{A M\left[\operatorname{Pr}_{c o n f a_{1}}, \operatorname{Pr}_{c o n f_{a_{2}}}\right](A \cap E)}{A M\left[\operatorname{Pr}_{c o n f} a_{1}, \operatorname{Pr}_{c o n f} a_{a_{2}}\right](E)}=\frac{5}{12}$. In Scenario II suppose (i) $\operatorname{Pr}_{\text {conf } a_{1}}(E)=\frac{1}{2}$ and $\operatorname{Pr}_{\text {conf } a_{2}}(E)=\frac{1}{2}$, (ii) $\operatorname{Pr}_{c o n f_{a_{1}}}(A \cap E)=\frac{1}{4}$ and $\operatorname{Pr}_{\text {conf } f_{2}}(A \cap E)=\frac{1}{8}$. Therefore, the new credence of the agent's equals the conditional aggregated credences $A M\left[\operatorname{Pr}_{\text {conf } a_{1}}, \operatorname{Pr}_{\text {con } f_{a_{2}}}\right](A \mid E)=$

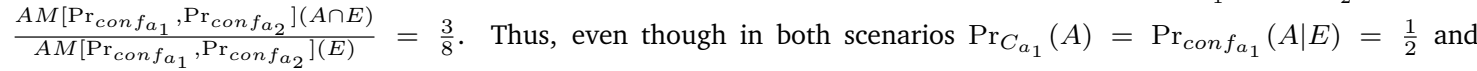
$\operatorname{Pr}_{C_{a_{2}}}(B)=\operatorname{Pr}_{\text {conf } f_{a_{2}}}(A \mid E)=\frac{1}{4}$ the aggregated credence in both scenarios differs. This shows that the aggregated credence is not a function of the credence of the individual agents. The reason for this result is that in both scenarios the agent's disagree in their confirmation commitments differently. After aggregating their confirmation commitments first, they come to different results in both scenarios with respect to the question what their aggregated credence should be.
} 
some proposition $A$ depend on $\operatorname{Pr}_{\text {conf } f_{a_{i}}}(A \cap E)$ and $\operatorname{Pr}_{\text {conf } f_{a_{i}}}(E)$, since $\operatorname{Pr}_{C_{a_{i}}}(A)=\frac{\operatorname{Pr}_{\text {conf }_{a_{i}}}(A \cap E)}{\operatorname{Pr}_{\text {conf }_{a_{i}}}(E)}$. This indicates that (AM*) does not satisfy requirement (IA), and for a good reason. According to Pluralistic Bayesianism, there is more to an agent's epistemic state that is epistemically relevant than the agent's credences. According to it the agent's confirmation commitments are epistemically relevant too, since they capture how the agent justifies her credences. It is for this reason that we reject (IA): if one disagrees with an agent on how to justify a certain proposition in the light of the evidence, one should not take that agent's credence in that proposition at face value. Instead, one should come to an agreement on how to justify the proposition in question by aggregating one's confirmation commitments first and only afterwards calculate the resulting credences. This requires considering more than just the agent's credences to determine her new epistemic state and the aggregated credences.

Now consider requirement (C). It requires that if a group of agents $G=\left\{a_{1}, \ldots, a_{n}\right\}$ aggregates their old credence functions $\operatorname{Pr}_{C_{a_{1}}}^{\text {old }}, \ldots, \operatorname{Pr}_{C_{a_{n}}}^{\text {old }}$, then their new credence in a proposition $A$, $A R\left[\operatorname{Pr}_{C_{a_{1}}}^{\text {old }}, \ldots, \operatorname{Pr}_{C_{a_{n}}}^{\text {old }}\right](A)$, is greater or equal to $\min \left\{\operatorname{Pr}_{C_{a_{i}}}^{\text {old }}(A): a_{i} \in G\right\}$ and smaller or equal to $\max \left\{\operatorname{Pr}_{C_{a_{i}}}^{\text {old }}(A): a_{i} \in G\right\}$. Aggregation rule $\left(\mathrm{GM}^{*}\right)$ does not satisfy this requirement. Just suppose again that two agents $a_{1}$ and $a_{2}$ received only the trivial evidence $E \cup \neg E$ and therefore $\operatorname{Pr}_{C_{a_{i}}}=\operatorname{Pr}_{\text {conf }_{a_{i}}}$ for both of them. We know from Section 2.2.2 (see Table 1) that (GM) does not satisfy (C) in this case. Again, since we assumed that the $\operatorname{Pr}_{C_{a_{i}}}=\operatorname{Pr}_{\text {conf } f_{a_{i}}}$ for both agents, this proves that $\left(\mathrm{GM}^{*}\right)$ does not satisfy $(\mathrm{C})$. Aggregation rule $\left(\mathrm{AM}^{*}\right)$ on the other hand satisfies (C) ${ }^{13}$, even if it reconciles the different credences of the agents indirectly by aggregating their

\footnotetext{
${ }^{13}$ Proof: Let $G$ be some group with agents $a_{1}, \ldots, a_{m}$ with confirmation commitments $\operatorname{Pr}_{\text {con } f_{a_{1}}}, \ldots, \operatorname{Pr}_{c o n} f_{a_{m}}$. We have to show that $\min \left\{\frac{\operatorname{Pr}_{\operatorname{conf} a_{i}}(H \cap E)}{\operatorname{Pr}_{c o n f a_{i}}(E)} \mid a_{i} \in G\right\} \leq \frac{A M\left[\operatorname{Pr}_{\text {conf } a_{1}}, \ldots \operatorname{Pr}_{\text {conf } a_{m}}\right](H \cap E)}{A M\left[\operatorname{Pr}_{\text {conf } f_{a_{1}}}, \ldots \operatorname{Pr}_{\text {conf } a_{m}}\right](E)} \leq \max \left\{\frac{\operatorname{Pr}_{\text {con } f_{a_{i}}}(H \cap E)}{\operatorname{Pr}_{\text {conf } f_{i}}(E)} \mid a_{i} \in G\right\}$. For induction base $n=1$ the proof is trivial. Now let us prove the inductive step: If $\min \left\{\frac{\operatorname{Pr}_{c o n f a_{i}}(H \cap E)}{\operatorname{Pr}_{c o n f} f_{a_{i}}(E)} \mid a_{i} \in\right.$ $G\} \leq \frac{A M\left[\operatorname{Pr}_{c o n f a_{1}}, \ldots \operatorname{Pr}_{c o n f a_{n}}\right](H \cap E)}{A M\left[\operatorname{Pr}_{c o n f a_{1}}, \ldots \operatorname{Pr}_{c o n f a_{n}}\right](E)} \leq \max \left\{\frac{\operatorname{Pr}_{c o n f a_{i}}(H \cap E)}{\operatorname{Pr}_{c o n f a_{i}}(E)} \mid a_{i} \in G\right\}$, then $\min \left\{\frac{\operatorname{Pr}_{\text {con } f_{a_{i}}}(H \cap E)}{\operatorname{Pr}_{\text {conf } a_{i}}(E)} \mid a_{i} \in G\right\} \leq$ $\frac{A M\left[\operatorname{Pr}_{\operatorname{con} f_{a_{1}}}, \ldots \operatorname{Pr}_{\operatorname{con} f_{a_{n+1}}}\right](H \cap E)}{A M\left[\operatorname{Pr}_{\operatorname{con} f_{a_{1}}}, \ldots \operatorname{Pr}_{\operatorname{con} f_{a_{n+1}}}\right](E)} \leq \max \left\{\frac{\operatorname{Pr}_{\operatorname{con} f_{a_{i}}}(H \cap E)}{\operatorname{Pr}_{\operatorname{con} f_{a_{i}}}(E)} \mid a_{i} \in G\right\}$. Without loss of generality let us assume that

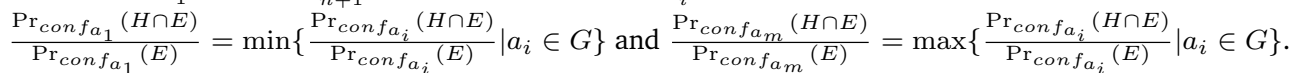

For the proof, suppose $\frac{\operatorname{Pr}_{c o n f a_{1}}(H \cap E)}{\operatorname{Pr}_{c o n f a_{1}}(E)} \leq \frac{A M\left[\operatorname{Pr}_{c o n f a_{1}}, \ldots \operatorname{Pr}_{c o n f a_{n}}\right](H \cap E)}{A M\left[\operatorname{Pr}_{c o n f a_{1}}, \ldots \operatorname{Pr}_{c o n f a_{n}}\right](E)} \leq \frac{\operatorname{Pr}_{c o n f a_{m}}(H \cap E)}{\operatorname{Pr}_{c o n f a_{m}}(E)}$. Thus, $\frac{\operatorname{Pr}_{c o n f a_{1}}(H \cap E)}{\operatorname{Pr}_{c o n f a_{1}}(E)} \leq$ $\frac{\sum_{j=1}^{n} w_{j}^{G} \times \operatorname{Pr}_{c o n f a_{j}}(H \cap E)}{\sum_{j=1}^{n} w_{j}^{G} \times \operatorname{Pr}_{c o n f_{a_{j}}}(E)} \leq \frac{\operatorname{Pr}_{\text {conf } a_{m}}(H \cap E)}{\operatorname{Pr}_{\text {con } f_{a_{m}}}(E)}$ by definition of (AM), whereas $w_{j}^{G} \in \mathbb{R}^{+}$and $\sum_{j=1}^{m} w_{j}^{G}=1$. By simple arithmetic it follows that $\operatorname{Pr}_{c o n f_{a_{1}}}(H \cap E) \times\left[\sum_{j=1}^{n} w_{j}^{G} \times \operatorname{Pr}_{c o n f_{a_{j}}}(E)\right] \leq \operatorname{Pr}_{\text {conf } a_{1}}(E) \times\left[\sum_{j=1}^{n} w_{j}^{G} \times \operatorname{Pr}_{c o n f a_{j}}(H \cap E)\right]$ and $\operatorname{Pr}_{c o n f_{a_{m}}}(E) \times\left[\sum_{j=1}^{n} w_{j}^{G} \times \operatorname{Pr}_{\text {conf } a_{j}}(H \cap E)\right] \leq \operatorname{Pr}_{\text {conf } a_{m}}(H \cap E) \times\left[\sum_{j=1}^{n} w_{j}^{G} \times \operatorname{Pr}_{c o n f_{a j}}(E)\right]$.

Now we also know by assumption that $\frac{\operatorname{Pr}_{c o n f a_{1}}(H \cap E)}{\operatorname{Pr}_{c o n f a_{1}}(E)} \leq \frac{\operatorname{Pr}_{\text {conf } f_{a_{n+1}}(H \cap E)}}{\operatorname{Pr}_{\text {conf } f_{n+1}}(E)} \leq \frac{\operatorname{Pr}_{\text {conf } a_{m}}(H \cap E)}{\operatorname{Pr}_{\text {conf }}(E)}$ and thus $\operatorname{Pr}_{\text {conf } a_{1}}(H \cap E) \times\left[\operatorname{Pr}_{c o n f_{a_{n+1}}}(E)\right] \leq \operatorname{Pr}_{\text {conf } a_{1}}(E) \times\left[\operatorname{Pr}_{\text {conf } f_{n+1}}(H \cap E)\right]$ and $\operatorname{Pr}_{\text {conf } a_{m}}(E) \times\left[\operatorname{Pr}_{c o n f a_{n+1}}(H \cap E)\right] \leq$ $\operatorname{Pr}_{\text {conf } a_{m}}(H \cap E) \times\left[\operatorname{Pr}_{c o n f} f_{a_{n+1}}(E)\right]$.

Therefore we can conclude that on the one hand $\operatorname{Pr}_{c o n f_{a_{1}}}(H \cap E) \times\left[\sum_{j=1}^{n} w_{j}^{G} \times \operatorname{Pr}_{\text {conf } a_{j}}(E)\right]+\operatorname{Pr}_{\text {conf } f_{1}}(H \cap E) \times$ $\left[w_{n+1}^{G} \operatorname{Pr}_{c o n f_{a_{n+1}}}(E)\right] \leq \operatorname{Pr}_{c o n f_{a_{1}}}(E) \times\left[\sum_{j=1}^{n} w_{j}^{G} \times \operatorname{Pr}_{c o n f_{a_{j}}}(H \cap E)\right]+\operatorname{Pr}_{c o n f_{a_{1}}}(E) \times\left[w_{n+1}^{G} \operatorname{Pr}_{c o n f_{a}+1}(H \cap E)\right]$, which implies as desired that $\frac{\operatorname{Pr}_{\text {conf } a_{1}}(H \cap E)}{\operatorname{Pr}_{\operatorname{con} f_{a_{1}}}(E)} \leq \frac{\sum_{j=1}^{n+1} w_{j}^{G} \times \operatorname{Pr}_{\operatorname{conf} a_{j}}(H \cap E)}{\sum_{j=1}^{n+1} w_{j}^{G} \times \operatorname{Pr}_{\operatorname{con} f_{a_{j}}}(E)}$.

On the other hand we can conclude that $\operatorname{Pr}_{\text {conf } f_{m}}(E) \times\left[\sum_{j=1}^{n} w_{j}^{G} \times \operatorname{Pr}_{\text {conf } a_{j}}(H \cap E)\right]+\operatorname{Pr}_{c o n f} f_{a_{m}}(E) \times$ $\left[w_{n+1}^{G} \operatorname{Pr}_{c o n f_{a_{n+1}}}(H \cap E)\right] \leq \operatorname{Pr}_{c o n f_{a_{m}}}(H \cap E) \times\left[\sum_{j=1}^{n} w_{j}^{G} \times \operatorname{Pr}_{c o n f_{a j}}(E)\right]+\operatorname{Pr}_{c o n f_{a m}}(H \cap E) \times$
} 
confirmation commitments first.

The next requirement (U) demands that if a group of agents $G=\left\{a_{1}, \ldots, a_{n}\right\}$ aggregates their old credence functions, $\operatorname{Pr}_{C_{a_{1}}}^{\text {old }}, \ldots, \operatorname{Pr}_{C_{a_{n}}}^{\text {old }}$, and all their old credences in a proposition $A, \operatorname{Pr}_{C_{a_{1}}}^{\text {old }}(A), \ldots \operatorname{Pr}_{C_{a_{n}}}^{\text {old }}(A)$, equal $r$, then their aggregated credence in $A, A R\left[\operatorname{Pr}_{C_{a_{1}}}^{\text {old }}, \ldots, \operatorname{Pr}_{C_{a_{n}}}^{\text {old }}\right](A)$, equals $r$ too. Again one can show that aggregation rule $\left(\mathrm{GM}^{*}\right)$ does not satisfy this requirement. Just suppose again that two agents $a_{1}$ and $a_{2}$ received only the trivial evidence $E \cup \neg E$ and therefore $\operatorname{Pr}_{C_{a_{i}}}=\operatorname{Pr}_{\text {conf }} f_{a_{i}}$ for both of them. We know from Section 2.2.2 (see Table 1) that (GM) does not satisfy (U) in this case. Hence, $\left(\mathrm{GM}^{*}\right)$ does not satisfy $(\mathrm{U})$ either. $\left(\mathrm{AM}^{*}\right)$, however, satisfies $(\mathrm{U})$, since it satisfies $(\mathrm{C})$ and the latter implies the former.

Now let us turn to the more sophisticated requirements. Requirement (CL) demands that an adequate aggregation rule is commutative with learning. It ensures that it is irrelevant whether one first aggregates epistemic states and afterwards incorporates new evidence, or whether one incorporates new evidence first and afterwards aggregates epistemic states (see also Jehle and Fitelson 2009: 286, Genest and Zideck 1986: 118). It also ensures that a group "will make decisions that appear to an outsider like the decisions of a single Bayesian agent" (Wagner 2010: 339). According to the picture we are promoting, this requirement is trivially satisfied by any possible aggregation rule (AR). Suppose two agents want to resolve their doxastic disagreement in the light of the same evidence. In particular, suppose $E S_{a_{1}}=\left\langle\operatorname{Pr}_{c o n f_{a_{1}}}, E\right\rangle$ and $E S_{a_{2}}=\left\langle\operatorname{Pr}_{\text {conf } a_{1}}, E\right\rangle$. Independently of whether both agents first learn $E^{\prime}$ and then resolve their doxastic disagreement or the other way around, we suggest that their new epistemic state is the following: $E S_{a_{i}}^{\text {new }}=$ $\left\langle A R\left[\operatorname{Pr}_{\text {conf } a_{a_{1}}} \operatorname{Pr}_{\text {conf } f_{a_{2}}}\right], E \cap E^{\prime}\right\rangle$. As a result the credence of both agents in some propositions $A$ equals $A R\left[\operatorname{Pr}_{\text {conf } f_{a_{1}}} \operatorname{Pr}_{\text {conf }_{a_{2}}}\right]\left(A \mid E \cap E^{\prime}\right)$. Since this holds for any possible aggregation rule it holds for $\left(\mathrm{AM}^{*}\right)$ and $\left(\mathrm{GM}^{*}\right)$ too. This is good news, since $(\mathrm{CL})$ is an indispensable requirement.

The (No-ZP) requirement demands that an agent (respectively, a group) is not forced to adopt credence (respectively to agree to an epistemic compromise) 0 in some proposition just because the other agent has credence 0 in that proposition. (GM*) does not satisfy this requirement. Suppose agent $a_{1}$ 's credence in some proposition $A$ in the light of evidence $E$ equals 0 . Thus, $\operatorname{Pr}_{\text {conf } a_{a_{1}}}(A \mid E)=0$ and therefore $\operatorname{Pr}_{\text {conf } a_{1}}(\omega)=0$ for all $\omega \in(A \cap E)$. By the definition of (GM) it follows that $G M\left[\operatorname{Pr}_{c o n f_{a_{1}}}, \ldots, \operatorname{Pr}_{\text {conf } f_{a_{n}}}\right](\omega)=0$, whenever $\operatorname{Pr}_{\text {conf } f_{a_{1}}}(\omega)=0$. Therefore $\left(\mathrm{GM}^{*}\right)$ does not satisfy (No-ZP). (AM*), however, satisfies (No-ZP). By the definition of (AM), $A M\left[\operatorname{Pr}_{\text {conf } a_{1}}, \ldots, \operatorname{Pr}_{\text {conf } a_{a_{n}}}\right](\omega)>0$, whenever for at least one agent $a_{i}: \operatorname{Pr}_{\text {conf } f_{a_{i}}}(\omega)>0$ (assuming that this agent has a positive weight, i.e., $w_{i}^{G}>0$ ). This demonstrates that (AM*) satisfies the indispensable requirement (No-ZP) and is in that respect preferable to $\left(\mathrm{GM}^{*}\right)$.

Finally, requirement (PI) demands that an adequate aggregation rule preserves initially-agreedupon judgements of probabilistic independence. As already noted, following Lehrer and Wagner

$\left[w_{n+1}^{G} \operatorname{Pr}_{c o n f_{a_{n+1}}}(E)\right]$, which implies as desired that $\frac{\sum_{j=1}^{n+1} w_{j}^{G} \times \operatorname{Pr}_{c o n f_{a_{j}}}(H \cap E)}{\sum_{j=1}^{n+1} w_{j}^{G} \times \operatorname{Pr}_{c o n f_{a_{j}}}(E)} \leq \frac{\operatorname{Pr}_{c o n f a_{m}}(H \cap E)}{\operatorname{Pr}_{c_{a n f} a_{m}}(E)}$. 
(1983) and Genest and Wagner (1987) this requirement is rejected by a number of philosophers and mathematicians. We do not want to take a definite stand concerning (PI). However, please note that neither $\left(\mathrm{AM}^{*}\right)$ nor $\left(\mathrm{GM}^{*}\right)$ satisfies (PI). We know from Section 2.2.2 (see Table 1) that (AM) and (GM) do not satisfy (PI). Now suppose again that two agents $a_{1}$ and $a_{2}$ received only the trivial evidence $E \cup \neg E$ and therefore $\operatorname{Pr}_{C_{a_{i}}}=\operatorname{Pr}_{c o n f_{a_{i}}}$ for both of them. By definition of $\left(\mathrm{AM}^{*}\right)$ and $\left(\mathrm{GM}^{*}\right)$, this implies that neither $\left(\mathrm{AM}^{*}\right)$ nor $\left(\mathrm{GM}^{*}\right)$ satisfies (PI).

The following table provides an overview of the results achieved:

\begin{tabular}{ccccccc} 
Aggregation Rule & $(\mathrm{IA})$ & $(\mathrm{C})$ & $(\mathrm{U})$ & $(\mathrm{CL})$ & $($ No-ZP) & $(\mathrm{PI})$ \\
\hline$\left(\mathrm{AM}^{*}\right)$ & No & Yes & Yes & Yes & Yes & No \\
$\left(\mathrm{GM}^{*}\right)$ & No & No & No & Yes & No & No
\end{tabular}

Table 2

Table 2 demonstrates that aggregation rule $\left(\mathrm{GM}^{*}\right)$ is inadequate from a philosophical point of view, since it does not satisfy any of the normative requirements except (CL). As before, that (GM*) satisfies the important requirement (CL) is not a sufficient reason for accepting it-especially if we compare it with aggregation rule $\left(\mathrm{AM}^{*}\right)$. The latter rule satisfies most requirements except (IA) and (PI). However, within the framework of Pluralistic Bayesianism we think it is actually a virtue of $\left(\mathrm{AM}^{*}\right)$ that it does not satisfy (IA). After all, Pluralistic Bayesianism is motivated by the consideration that there is more that is relevant to an agent's epistemic state than simply her credences. In particular, the agents' credences in some proposition $A$ depend on $\operatorname{Pr}_{\text {conf } a_{a_{i}}}(A \cap E)$ and $\operatorname{Pr}_{c o n f_{a_{i}}}(E)$, since $\operatorname{Pr}_{C_{a_{i}}}(A)=\frac{\operatorname{Pr}_{{\text {conf } a_{i}}_{i}}(A \cap E)}{\operatorname{Pr}_{\text {conf } a_{a_{i}}}(E)}$. Once we admit that the agents' evidence and their confirmation commitments are relevant too, it is natural to reject (IA) and instead to require that the aggregated credence function depends on $\operatorname{Pr}_{\text {conf } f_{a_{i}}}(A \cap E)$ and $\operatorname{Pr}_{\text {conf } f_{a_{i}}}(E)$. Thus, that $\left(\mathrm{AM}^{*}\right)$ does not preserve initially-agreed-upon judgements of probabilistic independence is not a reason to reject $\left(\mathrm{AM}^{*}\right)$. However, the satisfaction of all the normative requirements (C)-(No-ZP) is a good reason to adopt $\left(\mathrm{AM}^{*}\right)$.

\section{Conclusion}

We demonstrated that it is not possible to simultaneously satisfy all normative requirements on aggregation rules within Monistic Baysianism. Furthermore, within this framework there is no rule that satisfies our most important normative requirements, it is not even possible to model all forms of epistemic disagreement besides doxastic disagreement. In particular, within Monistic Bayesianism it is not possible to model evidential or confirmational disagreement.

If we revise our philosophical view that an agent's epistemic state is best represented by her credence function alone, we have the resources to overcome the mentioned shortcomings. When we adopt Pluralistic Bayesianism it is not only possible to model all forms of epistemic disagreement, but we also can provide an adequate aggregation rule that satisfies the most important normative 
requirements. The core philosophical idea of our solution is that if the agents involved in a doxastic disagreement all share the same (total) evidence, but disagree in their credences, then this must be due to a disagreement in their confirmation commitments. We suggested that the agents first agree on their confirmation commitments and thereby come to an agreement in credences as well. Based on this suggestion we formulated aggregation rule $\left(\mathrm{AM}^{*}\right)$ and showed that it satisfies the indispensable normative requirements (CL) and (No-ZP) and also the intuitive requirements (C) and (U). Since the alternative rule (GM*) does only satisfy (CL), (AM*) provides the best answer to the question of how to rationally revise one's epistemic state in the light of epistemic disagreement.

\section{References}

[1] Abbas, A. 2009. A Kullback-Leibler view of linear and log-linear pools. Decision Analysis, 6: $25-37$.

[2] Allard, D., Comunian, A. and P. Renard. 2012. Probability aggregation methods in geoscience. Mathematical Geosciences 44: 545-81.

[3] Christensen, D. 2009. Disagreement as evidence: the epistemology of controversy. Philosophy Compass 4: 756-67.

[4] Genest, C., McConway, K., and Schervish, M. 1986. Characterization of externally Bayesian pooling operators. The Annals of Statistics 14: 487-501.

[5] Genest, C. and Wagner, C. 1987. Further evidence against independence preservation in expert judgement synthesis. Aequationes Mathematicae 32: 74-86.

[6] Genest, C. and Zidek, J. 1986. Combining probability distributions: a critique and annotated bibliography. Statistical Science 1: 114-35.

[7] Greaves, H. and Wallace, D. 2006. Justifying conditionalization: conditionalization maximizes expected epistemic utility. Mind 115: 607-32.

[8] Hájek, A. 2011. Interpretations of probability. In E.N. Zalta (ed.), Stanford Encyclopedia of Philosophy.

[9] Jeffrey, R. 1987. Indefinite probability judgment. Philosophy of Science 54: 586-91.

[10] Jehle, D. and Fitelson, B. 2009. What is the "equal weight view"? Episteme 6: 280-93.

[11] Laddaga, R. 1977. Lehrer and the consensus proposal. Synthese 36: 473-7.

[12] Lange, M. 1999. Calibration and the epistemological role of Bayesian conditionalization. The Journal of Philosophy 96: 294-324.

[13] Lehrer, K. and Wagner, C. 1983. Probability amalgamation and the independence issue: a reply to Laddaga. Synthese 55: 339-46. 
[14] Levi, I. 1980. The Enterprise of Knowledge. Cambridge: MIT Press.

[15] McConway, K. 1981. Marginalization and linear opinion pools. Journal of the American Statistical Association 76: 410-4.

[16] Raiffa, H. 1968. Decision Analysis: Introductory Lectures on Choices under Uncertainty. Reading: Addison-Wesley.

[17] Wagner, C. 1982. Allocation, Lehrer models, and the consensus of probabilities. Theory and Decision 14: 207-220.

[18] Wagner, C. 2010. Jeffrey conditioning and external Bayesianity. Logic Journal of the IGPL 18: $336-45$.

[19] Williamson, J. 2010. In Defence of Objective Bayesianism. Oxford: Oxford University Press. 